\title{
Effects of ruminal ammonia and butyrate concentrations on reticuloruminal epithelial blood flow and volatile fatty acid absorption kinetics under washed reticulorumen conditions in lactating dairy cows
}

\author{
A. C. Storm, ${ }^{* 1}$ M. D. Hanigan, $†$ and N. B. Kristensen* \\ *Department of Animal Health and Bioscience, Faculty of Agricultural Sciences, Aarhus University, DK-8830 Tjele, Denmark \\ †Department of Dairy Science, Virginia Polytechnic Institute and State University, Blacksburg 24061
}

\begin{abstract}
The effect of reticuloruminal epithelial blood flow on the absorption of propionate as a volatile fatty acid (VFA) marker in 8 lactating Holstein cows was studied under washed rumen conditions. The cows were surgically prepared with ruminal cannulas and permanent catheters in an artery and mesenteric, right ruminal, and hepatic portal veins. The experiment was designed with 2 groups of cows: 4 cows adapted to high crude protein $(\mathrm{CP})$ and 4 to low $\mathrm{CP}$. All cows were subjected to 3 buffers: butyric, ammonia, and control in a randomized replicated $3 \times 3$ incomplete Latin square design. The buffers $(30 \mathrm{~kg})$ were maintained in a temporarily emptied and washed rumen for $40 \mathrm{~min}$. The initial concentration of VFA was $84.2 \mathrm{mmol} / \mathrm{L}$. Butyrate was increased from 4 to $36 \mathrm{mmol} / \mathrm{L}$ in butyric buffer by replacement of acetate, and ammonia $\left(\mathrm{NH}_{3}\right)$ was increased from 2.5 to $22.5 \mathrm{mmol} / \mathrm{L}$ in ammonia buffer by replacement of $\mathrm{NaCl}$. Increasing amounts of deuterium oxide $\left(\mathrm{D}_{2} \mathrm{O}\right)$ were added to the buffers as the order of buffer sequence increased $(6,12$, and $18 \mathrm{~g}$ of $\mathrm{D}_{2} \mathrm{O}$ ). Ruminal clearance of $\mathrm{D}_{2} \mathrm{O}$ was used to estimate epithelial blood flow. To increase accuracy of the epithelial blood flow estimates, data of ruminal liquid marker (Cr-EDTA), and initial and final buffer volumes were fitted to a dynamic simulation model. The model was used to estimate ruminal liquid passages, residual liquid, and water influx (saliva and epithelia water) for each combination of cow and buffer $(\mathrm{n}=24)$. Epithelial blood flow increased $49 \pm 11 \%$ for butyric buffer compared with control. The ruminal disappearance of propionate (marker VFA) was affected by buffer and followed the same pattern as for epithelial blood flow. The correlation between ruminal disappearance of propionate and epithelial blood flow $(\mathrm{r}=0.56)$ indicates that the removal of propionate can be limited by epithelial blood flow. The ruminal disappearance of
\end{abstract}

Received December 14, 2010.

Accepted March 25, 2011.

${ }^{1}$ Corresponding author: adam.storm@agrsci.dk propionate increased $30 \pm 12 \%$ for the butyric compared with ammonia buffer and $12.5 \pm 8 \%$ when compared with control. The net portal flux of propionate increased $32 \pm 6 \%$ in butyric compared with control. In conclusion, rumen epithelial blood flow is positively correlated with ruminal disappearance of propionate and affects the kinetics of ruminal VFA absorption.

Key words: reticuloruminal epithelium, epithelial blood flow, volatile fatty acid kinetics, dairy cow

\section{INTRODUCTION}

Volatile fatty acids of forestomach origin are continuously absorbed across the papillated epithelium of the reticulorumen or washed out of the rumen by liquid passage (Peters et al., 1990). The rate of absorption is dependent on the VFA concentration in the ruminal epithelium, the chemical properties of VFA, and $\mathrm{pH}$ (Dijkstra et al., 1993; Kristensen and Harmon, 2004b). However, VFA removal from the serosal side of the epithelium by blood might be important in controlling the net transepithelial flux of VFA and thereby the ruminal equilibrium concentration at a given production rate of VFA.

The most common theory of ruminal absorption of VFA is passive diffusion of non-ionized VFA. However, the patterns of ruminal disappearance of acetate, propionate, and butyrate are not consistent with the expected changes in ionization according to the HendersonHasselbalch equation as ruminal $\mathrm{pH}$ declines (Dijkstra et al., 1993). The deviations in patterns of acetate and propionate absorption are thought to be due to saturation of a co-transporter at the luminal or serosal side of the epithelium (Aschenbach et al., 2009). If the rumen epithelial blood flow is relatively low compared with the permeability of the epithelium to VFA, then the ruminal absorption of VFA will be limited more by changes in epithelial blood flow than by changes in VFA permeability. Therefore, ruminal VFA absorption kinetics may also be affected by changes in rumen fluid to epithelial blood concentration differences of VFA via changes in epithelial blood flow. 
Lactating dairy cows have net portal VFA absorption rates of approximately $99 \mathrm{~mol} / \mathrm{d}$ of VFA with diurnal variation ranging from 3.3 to $5.0 \mathrm{~mol} / \mathrm{h}$ (Storm and Kristensen, 2010, 2011). The diurnal variation associated with changes in portal blood flow. The postprandial increase in portal blood flow is, according to Barnes et al. (1983), solely related to an increase in the ruminal vein blood flow when measured in sheep. The microsphere technique applied to sheep was used to estimate the blood flow and partitioning between muscle and epithelium of the reticulorumen (Von Engelhardt and Hales, 1977; Barnes et al., 1983). These studies indicated that 92 to $95 \%$ of the reticuloruminal blood flow was epithelial blood flow. Right ruminal artery blood flow in lactating dairy cows was 96 to $125 \mathrm{~L} / \mathrm{h}$ (Girard et al., 2009; Girard and Desrochers, 2010), indicating that 177 to $238 \mathrm{~L} / \mathrm{h}$ of blood flows through the epithelium. However, nutrient absorption from the reticulorumen is affected by exposure of the epithelium to ruminal fluid (Dijkstra et al., 1993). Because of the separation of ruminal contents into gas, particulate matter, and free ruminal fluid (Allen, 1996), ruminal VFA are primarily absorbed from the ventral rumen in agreement with the denser papillation of this region compared with the dorsal rumen (Scott and Gardner, 1973). Effective epithelial blood flow to the reticulorumen absorptive area is therefore not equal to total epithelial blood flow due to the greater exposure of ruminal fluid to the ventral rumen compared with the dorsal rumen. Dobson et al. (1971) used tritiated water clearance from the rumen of dry cows to determine reticulorumen epithelial blood flow. Ruminal butyrate and high ruminal carbon dioxide partial pressure were shown to be the most potent stimuli of tritiated water clearance. However, direct measurements of ruminal disappearance of VFA and net portal flux in relation to absorptive epithelial blood flow and labeled water clearance has not yet been studied in lactating dairy cows.

The hypothesis of the present study was that effective reticulorumen epithelial blood flow is important in control of net transepithelial VFA flux and thereby the efficiency by which VFA is absorbed from ruminal fluid. The primary objective of the study was to investigate the effect of varying epithelial blood flow on net absorption of VFA. A secondary objective was to evaluate the potential effects of dietary crude protein on epithelial blood flow and VFA absorption.

\section{MATERIALS AND METHODS}

The present experiment complied with Danish Ministry of Justice Law no. 382 (June 10, 1987) Act no. 726 (September 9, 1993), concerning experiments with animals and the care of experimental animals.

\section{Animals and Feeding}

The present study was conducted using cows (565 \pm $16 \mathrm{~kg}$ of BW; $63 \pm 1 \mathrm{DIM})$ fed a low or a high protein diet (low CP $12.9 \%$, high CP $17.1 \%$, fed ad libitum) in a crossover design as described previously (Kristensen et al., 2010). Samplings presented in the present paper were conducted 1 wk after the urea flux measurement, and cows had been fed the experimental diets for 21 d when sampled. Eight lactating, Danish Holstein, second-parity cows were used for the study. The cows were surgically prepared with ruminal cannulas (\#1C; Bar Diamond, Parma, ID) and permanent catheters in a mesenteric or intercostal artery as well as in the mesenteric, right ruminal, and hepatic portal veins.

\section{Experimental Design and Treatments}

The experimental design was a split-plot design with dietary CP concentration as the whole plot factor and buffer treatment as subplot factor. The buffer treatments were arranged as a replicated incomplete $3 \times$ 3 Latin square. Treatment buffers (butyric, ammonia, control) and wash buffer were prepared according to Table 1 and adjusted to $\mathrm{pH} 6.7$.

Deuterium oxide $\left(\mathrm{D}_{2} \mathrm{O}\right)$ was combined with the treatment buffers in increasing amounts $(6,12$, and $18 \mathrm{~g} / 30$ L; Aldrich 99.9\%; Sigma-Aldrich Chemie GmbH, Steinheim, Germany) according to the buffer sequence for estimation of reticuloruminal epithelial blood flow. The liquid marker (Cr-EDTA, $0.11 \mathrm{mmol} / \mathrm{L}$ ) was combined with treatment buffers for estimation of ruminal liquid passages (Binnerts et al., 1968).

\section{Experimental Samplings}

On sampling days, a continuous infusion of $p$-aminohippuric acid (pAH; $29.3 \pm 1.2 \mathrm{mmol} / \mathrm{h}$ ) into the mesenteric vein was initiated at least $75 \mathrm{~min}$ before introduction of the first buffer. The infusate was a 175 $\mathrm{m} M$ solution of pAH (4-aminohippuric acid 99\%, Acros, Geel, Belgium) adjusted to $\mathrm{pH}$ 7.4, filtered (Filter Top PES membrane $0.22 \mu \mathrm{m}$; Techno Plastic Products AG, Trasadingen, Switzerland), and autoclaved. Ruminal contents were evacuated, and the rumen wall was thoroughly washed with lukewarm tap water (approximately $40^{\circ} \mathrm{C}$ ) followed by 3 rinses with lukewarm $0.9 \%$ saline $(10 \mathrm{~kg} /$ rinse). The buffers were introduced into the rumen in 3 sequences of wash buffer $(20 \mathrm{~kg}$ in 20 min) and treatment buffer (30 kg in $40 \mathrm{~min}$; Figure 1). All buffers were weighed and sampled before ruminal introduction. In vivo mixing of the buffers was accomplished by continuous infusion of a gas mixture $(70 \%$ $\mathrm{CO}_{2} / 30 \% \mathrm{~N}_{2}$ ) into the ventral rumen using a device de- 
Table 1. Composition of experimental buffers ${ }^{1}(\mathrm{mmol} / \mathrm{L})$

\begin{tabular}{lcccc}
\hline Item & $\begin{array}{c}\text { Wash } \\
\text { buffer }\end{array}$ & Ammonia & Butyric & Control \\
\hline Acetic acid & 0 & 55.0 & 23.0 & 55.0 \\
Propionic acid & 0 & 22.0 & 22.0 & 22.0 \\
Isobutyric acid & 0 & 2.0 & 2.0 & 2.0 \\
Butyric acid & 0 & 4.0 & 36.0 & 4.0 \\
Valeric acid & 0 & 1.2 & 1.2 & 1.2 \\
Urea & 0 & 12.5 & 12.5 & 2.5 \\
$\mathrm{NH}{ }_{4} \mathrm{Cl}$ & 0 & 0 & 2.5 & 20 \\
$\mathrm{NaCl}$ & 106 & 24 & 20 & 24 \\
$\mathrm{NaHCO}$ & 24 & 77 & 77 & 77 \\
$\mathrm{NaOH}$ & 0 & 20 & 20 & 20 \\
$\mathrm{KOH}$ & 20 & 2 & 2 & 2 \\
$\mathrm{~K}_{2} \mathrm{HPO}$ & 2 & 1.5 & 1.5 & 1.5 \\
$\mathrm{CaCl}$ & 1.5 & 0.11 & 1.5 & 1.5 \\
$\mathrm{MgCl}_{2}$ & 1.5 & 0.11 & 0.11 \\
$\mathrm{Cr}_{2}-\mathrm{EDTA}$ & 0 & 1.5 & 2.5 \\
\hline
\end{tabular}

${ }^{1}$ The ruminal buffers were agitated by gas with a $70 \% \mathrm{CO}_{2}: 30 \% \mathrm{~N}_{2}$ gas mixture. $\mathrm{pH}$ of the buffers was 6.7 before ruminal introduction.

scribed by Kristensen et al. (2002). After each infusion, residual ruminal buffer was removed by vacuum, and the rumen was washed with $10 \mathrm{~kg}$ of $0.9 \%$ saline (also removed by vacuum) before the next buffer sequence. Residual buffer and the saline wash were combined, weighed, and sampled.

For each sequence (wash buffer followed by treatment buffer), 5 sets of arterial, portal, and ruminal vein blood samples and ruminal buffer samples were simultaneously drawn at time points of 15 min after introduction of the wash buffer and 3,9,20, and $30 \mathrm{~min}$ after introduction of the treatment buffer, resulting in 15 sets of samples per cow per day. For each sample time, 1 blood sample was drawn into a 1-mL heparinized syringe for blood gas and oximetry measurements. A second blood sample of $20 \mathrm{~mL}$ was drawn from each catheter and transferred into heparin vacuettes (\#455051; Greiner BioOne GmbH, Kremsmuenster, Austria) and centrifuged at $3,000 \times g$ for $20 \mathrm{~min}$ at $4^{\circ} \mathrm{C}$. The resulting plasma was stored at $-20^{\circ} \mathrm{C}$. The ruminal buffer was sampled through the ruminal can- nula using silicone tubing (\#39339, $1 \mathrm{~mm}$ i.d., $3 \mathrm{~mm}$ o.d.; Ole Dich Instrumentmakers, Hvidovre, Denmark) fixed in the ventral rumen by a weight. Two 50-mL samples of ruminal buffer were extracted by syringe. The first was dispatched back into the rumen and the second was used for analytic purposes. Ventral ruminal buffer $\mathrm{pH}$ was measured immediately using a combination electrode (PHC2002-8; Hach Lange APS, Brønsh $\varnothing$ j, Denmark) and a $\mathrm{pH}$ meter calibrated at $\mathrm{pH}$ 4.0 and 7.0 (PHM 240; Hach Lange APS). Two 8-mL subsamples of ruminal buffer, one combined with $2 \mathrm{~mL}$ of $25 \%$ metaphosphoric acid and one unstabilized, were stored at $-20^{\circ} \mathrm{C}$.

\section{Analytical Procedures}

Ruminal buffer VFA (acetate, propionate, butyrate, isobutyrate, and valerate) concentrations were analyzed by GC (Kristensen et al., 1996). Ruminal buffer $\mathrm{NH}_{3}$ was analyzed using a Cobas Mira autoanalyzer (Triolab A/S, Brøndby, Denmark) with a kit based on glutamate

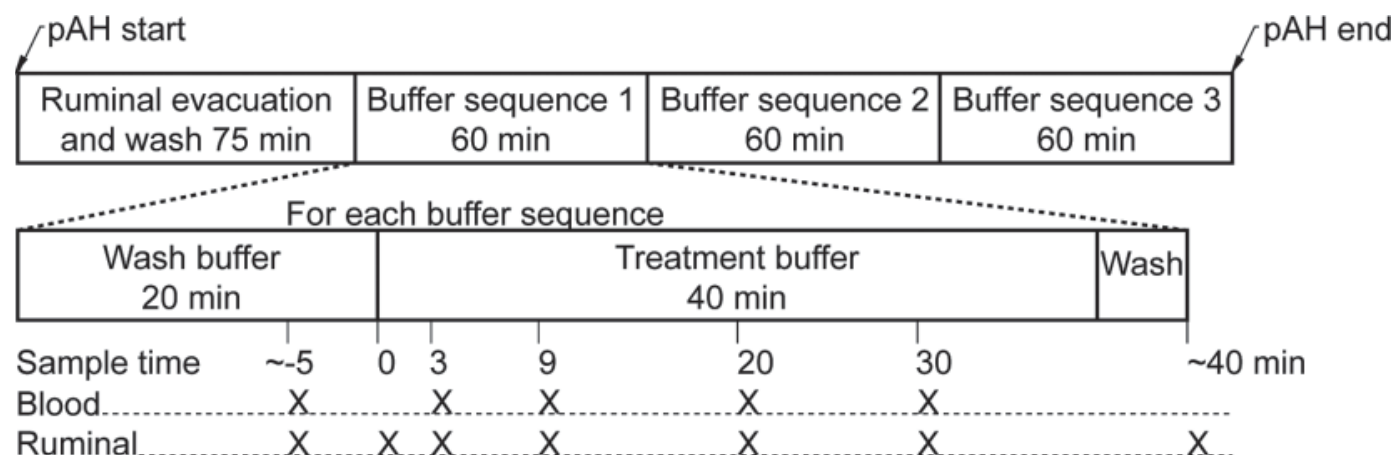

Figure 1. Experimental design and sampling procedure of the washed rumen experiment. $\mathrm{pAH}=p$-aminohippuric acid. 


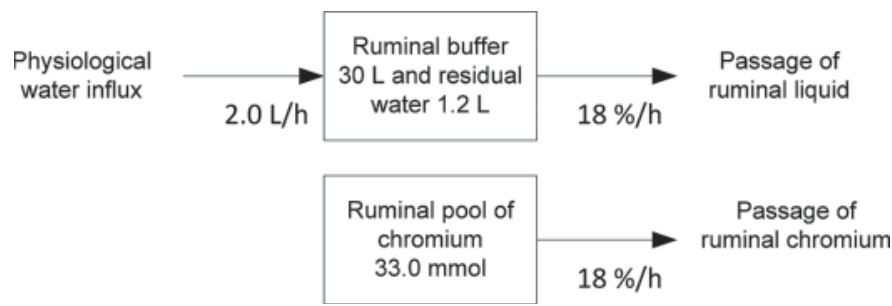

Figure 2. Flow diagram of the dynamic simulation model of ruminal liquid flow under washed rumen conditions. Boxes represent the volume of ruminal liquid and pool of ruminal Cr-EDTA; arrows represent fluxes and flow. The values under the arrows represent the mean parameter estimates for passage rate constant and physiological water influx.

dehydrogenase (Ranbut; Randox Laboratories Ltd., Crumlin, UK). Ruminal buffer urea was analyzed by the method of Marsh et al. (1965) using a continuous flow analyzer (Autoanalyser 3, method G-373-07 Rev.1; Seal Analytical Ltd., Burgess Hill, UK). Ruminal buffer $\mathrm{Cr}$ was analyzed by atomic absorption spectroscopy $(357.9 \mathrm{~nm})$ after centrifugation at 4,000 $\times g$ for $10 \mathrm{~min}$ at $20^{\circ} \mathrm{C}$ (Williams et al., 1962).

The packed blood cell volume (hematocrit) was measured for samples collected at the 30-min time point by whole blood centrifugation in capillary tubes at 13,000 $\times g$ for 6 min at ambient temperature. The $1-\mathrm{mL}$ syringes of blood from the 3 catheters were immediately taken for blood gas and oximetry analysis (ABL 700; Radiometer A/S, Copenhagen, Denmark). Plasma concentrations of urea and $\mathrm{NH}_{3}$ were analyzed as for ruminal buffer described above. Plasma glucose and L-lactate were analyzed (D-glucose oxidase, L-lactate oxidase, respectively) using a YSI analyzer (YSI 7100; YSI Inc., Yellow Springs, OH). Plasma pAH was analyzed as described by Harvey and Brothers (1962) using a continuous flow analyzer (Autoanalyzer 3, method US-216-72 Rev.1; Seal Analytical Ltd.). Plasma concentrations of VFA (acetate, propionate, butyrate, isobutyrate, and valerate) were analyzed by GC (Kristensen, 2000) using a mass spectrometer as a detector (DSQ; Thermo Electron, Austin, TX). Plasma concentrations of BHBA were determined using a Cobas Mira autoanalyzer with a $\beta$-hydroxybutyrate dehydrogenase kit (Ranbut; Randox Laboratories Ltd.).

Plasma and ruminal buffer samples were analyzed for $\mathrm{D}_{2} \mathrm{O}$ by high temperature conversion elemental analysis-isotope ratio mass spectrometry (Finnigan Delta V Plus, Thermo Scientific, Bremen, Germany). Plasma and ruminal buffer water were separated by ultrafiltration $[250 \mu \mathrm{L}$ of plasma, $10 \mathrm{kDa}$ filter (Pall Nanosep10K Omega, VWR Bie \& Berntsen A/S, Herlev, Denmark), $\left.10,000 \times g, 20 \mathrm{~min}, 32^{\circ} \mathrm{C}\right]$ before injection.

\section{Model Derivation}

The purpose of the current model was to predict ruminal liquid passage, residual ruminal water in the rumen upon buffer entry and the physiological water influx (saliva and net flux of water across the ruminal epithelium) individually for each trial. The passage rate constant $\left(K_{R u, L i q}\right)$, the volume of residual ruminal water $\left(V_{R u, r H 2 O}\right)$, and the physiological water influx $\left(F_{\text {Sal,Liq }}\right)$ were estimated for each combination of cow and buffer from observed data resulting in 24 sets of estimates $(8$ cows and 3 buffers). These estimates were later used in the numerical calculations of ruminal clearance to increase the accuracy. The model consisted of a set of dynamic differential equations coded in the Advanced Continuous Simulation Language (Acsl Extreme; Aegis Technologies Group Inc., Huntsville, AL). A flow diagram of the model is presented in Figure 2. The general nomenclature for variables is as follows: mass $(\boldsymbol{Q}, \mathrm{mmol})$, volume $(\boldsymbol{V}, \mathrm{L})$, concentration $(\boldsymbol{C}$, mmol/L), flow/flux $(\boldsymbol{F}$, when liquid flow, L/h, and when $\mathrm{Cr}, \mathrm{mmol} / \mathrm{h}$ flux $)$, and rate constants $(\boldsymbol{k}, \% / \mathrm{h})$. Abbreviations generally follow the form of $A_{b, c}$ were $A$ is the variable type $(Q, V, C, F, k), b$ is the pool of interest, buffer $(\boldsymbol{B u f})$ or ruminal $(\boldsymbol{R} \boldsymbol{u})$, and $c$ is the item of concern, liquid $(\boldsymbol{L} \boldsymbol{i q})$, Cr-EDTA $(\boldsymbol{C r})$, ruminal residual water $\left(\boldsymbol{r} \boldsymbol{H}_{2} \boldsymbol{O}\right)$, and physiological water influx $(\boldsymbol{S a l})$. The model consists of 2 primary state variables: the ruminal volume of liquid $\left(V_{R u, L i q}\right)$ and the ruminal pool of Cr-EDTA $\left(Q_{R u, C r}\right)$. The physiological water influx was considered constant, and the passage of liquid out of the rumen $\left(\mathrm{F}_{R u, L i q}\right)$ was considered to be driven by mass action. The model was fitted against observed data including Cr-EDTA concentrations $\left(C_{R u, C r}\right)$ in the ruminal buffers at time $3,9,20$, and 30 and the initial concentration in the buffer $\left(i C_{B u f, C r}\right)$, as well as the initial buffer volume $\left(i V_{B u f, L i q}\right)$ and final buffer volume. Outputs were the ruminal volume of liquid $\left(V_{R u, L i q}\right)$ and ruminal pool of $\mathrm{Cr}\left(Q_{R u, C r}\right)$. The differential equations describing the changes in $V_{R u, L i q}, Q_{R u, C r}$ with respect to time $(t)$ were

$$
\frac{\mathrm{d} V_{R u, L i q}}{\mathrm{~d} t}=F_{R u, S a l}-F_{R u, L i q}
$$

and

$$
\frac{\mathrm{d} Q_{R u, C r}}{\mathrm{~d} t}=-F_{R u, C r} .
$$

The $F_{R u, S a l}$ was constant and passage of liquid $F_{R u, L i q}$ and Cr-EDTA $F_{R u, C r}$ out of the rumen were mass-action regulated and calculated as 


$$
F_{R u, L i q}=V_{R u, L i q} \times k_{R u, L i q}
$$

and

$$
F_{R u, C r}=Q_{R u, C r} \times k_{R u, C r} .
$$

The rate constants for liquid and $\mathrm{Cr}$ passage were assumed equal. The initial liquid volumes, ruminal $\mathrm{Cr}$ concentrations, and quantum of $\mathrm{Cr}$ were calculated as

$$
\begin{aligned}
& i V_{R u, L i q}=i V_{B u f, L i q}+i V_{R u, r H_{2} O}, \\
& i C_{R u, C r}=\frac{i C_{B u f, C r} \times i V_{B u f, L i q}}{i V_{B u f, L i q}+i V_{R u, r H_{2} O}},
\end{aligned}
$$

and

$$
i Q_{R u, C r}=i C_{R u, C r} \times i V_{R u, L i q}
$$

The ruminal liquid volume and the ruminal $\mathrm{Cr}$ pool were derived by numerical integration of the respective differential equations:

$$
V_{R u, L i q}=\int_{0}^{t} \mathrm{~d} V_{R u, L i q}+i V_{R u, L i q}
$$

and

$$
Q_{R u, C r}=\int_{0}^{t} \mathrm{~d} Q_{R u, C r}+i Q_{R u, C r} .
$$

\section{Parameter Estimation}

The parameter estimation of the rate constants related to the passages of liquid, the volume of ruminal water residues, and the ruminal physiological water influx were estimated by fitting the model to the observed data using the Nelder-Mead algorithm to maximize the likelihood function (Ver. 11.8. Aegis Technologies Group Inc.).

\section{Calculations and Statistical Procedures}

The following calculations in equations [10] to [17] were done on observed data using the 24 sets of parameter estimates from the model section to assess the ruminal liquid volume, pool of metabolites, disappearance of metabolites, clearance of metabolites, epithelial blood flow, and ruminal vein recovery. Abbreviations of general calculations follow the extended form of the model derivation $A_{b, c, d}$, unless written otherwise, where $A$ is the variable type $(Q, V, C, F, k)$, including ruminal clearance $(R C, \mathrm{~L} / \mathrm{h}), b$ is the pool of interest, (Buf, $R u$ ), including ruminal vein blood $(R v)$ and arterial blood $(A), c$ is related to the item of interest ( $L i q, C r$ ) including metabolites $\left(x=V F A, D_{2} O\right)$, and $d$ is related to time $(t-1, t, \Delta t)$. The initial concentrations of metabolites in ruminal buffer and ruminal volume of liquid at time zero were calculated according to equations [6] and [5], respectively. The ruminal liquid volume was numerically calculated as

$$
\begin{aligned}
V_{R u, L i q,(t)} & =V_{R u, L i q,(t-1)}-V_{R u, L i q,(t-1)} \\
& \times k_{R u, L i q} \times(\Delta t)+F_{R u, S a l} \times(\Delta t) .
\end{aligned}
$$

The ruminal pools of metabolites were calculated as

$$
Q_{R u, x,(t)}=V_{R u, L i q,(t)} \times C_{R u, x,(t)} .
$$

Ruminal disappearance of metabolites corrected for passage loss and metabolite influx with physiological water was calculated as

$$
F_{R u, x,(t)}=\frac{Q_{R u, x,(t-1)}-Q_{R u, x,(t)}-F_{L i q, x,(\Delta t)}+F_{S a l, x,(\Delta t)}}{\Delta t},
$$

where the ruminal passages and physiological influx of metabolites were calculated as equations [13] and [14], respectively:

$$
F_{L i q, x,(\Delta t)}=V_{R u, L i q,(t-1)} \times k_{R u, L i q}
$$

$$
\times(\Delta t) \times\left(\frac{C_{R u, x,(t-1)}+C_{R u, x,(t)}}{2}\right)
$$

and

$$
F_{S a l, x,(\Delta t)}=F_{R u, S a l} \times(\Delta t) \times\left(\frac{C_{A, x,(t-1)}+C_{A, x,(t)}}{2}\right),
$$

where $F_{R u, S a l}$ is constant. The ruminal clearance of metabolites was calculated as

$$
R C_{R u, x,(t)}=\frac{F_{R u, x,(t)}}{\left(\frac{C_{R u, x,(t-1)}+C_{R u, x,(t)}}{2}\right)-\left(\frac{C_{A, x,(t-1)}+C_{A, x,(t)}}{2}\right)} .
$$


The reticuloruminal epithelial blood flow was calculated as ruminal clearance of $\mathrm{D}_{2} \mathrm{O}$ (equation [16]), assuming that the reticuloruminal epithelium and associated blood were in full equilibrium with ruminal $\mathrm{D}_{2} \mathrm{O}$. The ruminal vein blood flow $(R V B F)$ was calculated as

$$
R V B F=\frac{R C_{R u, D_{2} O,(t)}}{\left(C_{R v, D_{2} O,(t)}-C_{A, D_{2} O,(t)}\right) /\left(C_{R u, D_{2} O,(t)}-C_{A, D_{2} O,(t)}\right)} .
$$

Plasma flow in the hepatic portal vein and net portal flux were calculated according to Kristensen et al. (2007). In short, the net portal flux was the concentration difference between the portal and arterial blood times the portal blood flow. A positive flux describes a net release, and a negative flux describes a net uptake of metabolites in the portal-drained viscera. Ruminal vein recovery of ruminal VFA was calculated as:

$$
\text { Ruminal Vein Recovery }=\frac{R V B F \times C_{R v, x,(t)}}{F_{R u, x,(t)}} .
$$

For results on feed intake and production level, we refer to Kristensen et al. (2010). One cow on the low $\mathrm{CP}$ diet had a misplaced portal vein catheter; hence, data from the portal vein samples for that cow have been excluded. Two cows on the low CP diet had a malfunctioning ruminal vein catheter; hence, no ruminal vein samples were drawn from those cows. All other samples were collected as planned.

Data were analyzed using the MIXED procedure of SAS (SAS Institute, 2003). For longitudinal data, only sample times $+9,+20$, and +30 min after introduction of the buffers were used in the statistical analyses. Data from the sample at +3 min were not used for statistical purposes because the flux estimates between 0 and +3 min may be affected more by the epithelial pools filling up than by actual release of the compounds to the ruminal vein. We used cow $\times \mathrm{CP}$ level and buffer $\times$ period (buffer sequence) as random effects, including fixed effects of CP level, buffer, time (sample time), period, and interactions among buffer, time and $\mathrm{CP}$ level. Sample time was considered as repeated measurements. The spatial Gaussian covariate structure was used because of the heterogenic distribution of data points. For statistical analyses of data at the last sampling $(+30 \mathrm{~min})$, we used cow $\times \mathrm{CP}$ level as random effects, including fixed effects of $\mathrm{CP}$ level, buffer, period, and interactions among buffer, and CP level. Correlations between epithelial blood flow and ruminal disappearance of propionate were analyzed using the CORR procedure of SAS (SAS Institute, 2003). Correlations are presented as Pearson correlation coefficients and $P$-values. Data are presented as LS means \pm residual standard error of the mean except for overall means, which are presented as mean \pm standard error of the mean. Significance was declared at $P<0.05$ and tendencies considered at $P<0.10$.

\section{RESULTS}

\section{Initial Buffer Variables}

Only the initial buffer concentrations of acetate, butyrate, and $\mathrm{NH}_{3}$ were intended to differ among the buffers (Table 1). The initial buffer concentrations of acetate, butyrate, and $\mathrm{NH}_{3}$ were $55 \pm 0.5,4 \pm 0.1$, and $18 \pm 0.5 \mathrm{mmol} / \mathrm{L}$ for ammonia, $23 \pm 0.5,37 \pm$ 0.1 , and $1.3 \pm 0.5 \mathrm{mmol} / \mathrm{L}$ for butyric, and $54 \pm 0.5,4$ \pm 0.1 , and $1.7 \pm 0.5 \mathrm{mmol} / \mathrm{L}$ for control, respectively. The initial concentrations of propionate and urea did not differ $(P>0.21)$. Initial isobutyrate and valerate concentrations were $0.064 \pm 0.014$ and $0.017 \pm 0.008$ $\mathrm{mmol} / \mathrm{L}$ greater in the butyric treatment than in the ammonia and control treatments $(P<0.01, P=0.07)$, respectively. Differences among buffers in isobutyrate and valerate were numerically small and were considered not to affect the results.

\section{Ruminal Buffer Variables}

Ruminal buffer passage, ruminal physiological water influx, and residual ruminal water were estimated individually for each combination of cow and buffer; results are presented in Table 2 .

The ruminal concentrations of VFA, urea, and $\mathrm{D}_{2} \mathrm{O}$ decreased with time (Figure 3 ). The relative $\mathrm{D}_{2} \mathrm{O}$ concentration difference among buffers at the last sampling time in each buffer sequence $(+30 \mathrm{~min})$ was 13 $\pm 2.6 \%$ lower $(P<0.01)$ in butyric compared with ammonia. Ruminal $\mathrm{NH}_{3}$ concentrations increased with butyric and control treatment but were stable throughout the ammonia buffer exposure. Ruminal urea concentration decreased for all buffers during the ruminal exposure. The rates of decrease were less for ammonia compared with butyric and control $(P<0.01)$. The mean concentration of urea at the last sampling was $2.28 \pm 0.58,3.89 \pm 0.58$, and $2.35 \pm 0.58 \mathrm{mmol} / \mathrm{L}$ in control, ammonia, and butyric, respectively. Ruminal disappearance of propionate tended to be affected by buffer $(P=0.06)$, with no effect of CP level $(P=0.12)$. Butyric buffer exposure increased ruminal disappearance of propionate by $30 \pm 11.8 \%$ from 276 to $359 \pm 26$ $\mathrm{mmol} / \mathrm{h}$ compared with ammonia $(P=0.03)$ and 12.5 $\pm 8 \%$ compared with control $(P=0.17)$. 
Table 2. Parameter estimates derived from fitting the model to observed data of ruminal Cr-EDTA concentration and buffer volume upon ruminal entry and exit for each combination of cow and buffer $(\mathrm{n}=24)$

\begin{tabular}{|c|c|c|c|c|}
\hline \multirow[b]{2}{*}{ Parameter } & \multicolumn{2}{|c|}{ Estimate } & \multirow[b]{2}{*}{ Mean SE } & \multirow{2}{*}{$\begin{array}{l}\text { Mean SE \% } \\
\text { of estimate }\end{array}$} \\
\hline & Minimum & Maximum & & \\
\hline Rate constant for passage, $\% / \mathrm{h}$ & 0.00 & 32.1 & $5.68 \times 10^{-06}$ & $3.26 \times 10^{-03}$ \\
\hline Ruminal water residues, L & 0.02 & 3.0 & $5.14 \times 10^{-05}$ & $4.13 \times 10^{-03}$ \\
\hline Physiological water influx, $\mathrm{L} / \mathrm{h}$ & -1.5 & 8.1 & $7.99 \times 10^{-05}$ & $3.51 \times 10^{-03}$ \\
\hline
\end{tabular}

\section{Arterial Variables}

Arterial concentrations of propionate, butyrate, BHBA, and $\mathrm{NH}_{3}$ all increased $(P<0.01, P<0.01$, $P<0.01, P=0.03$, respectively) in treatment buffers compared with wash-buffer periods.

The arterial blood $\mathrm{pH}$ was not affected by any factors or interactions $(P>0.08$; Table 3$)$. Arterial blood concentration of acetate decreased with time $(P<$ 0.01 ) and was most apparent between time points 3 and 4 . The arterial blood concentration of propionate was $163 \pm 39 \%$ higher with butyric compared with control $(P<0.01)$. Arterial blood concentrations of butyrate was $786 \pm 92 \%$ higher in butyric compared with control $(P<0.01)$. The interaction between buffer and time $(P<0.01)$ indicated that arterial butyrate decreased between time points 3 and 4 when exposed to butyric buffer. Arterial isobutyrate was affected by the interaction between buffer and time $(P<0.01)$, indicating an increase in arterial isobutyrate with butyric buffer exposure and a decrease with ammonia buffer exposure when compared with control at time point

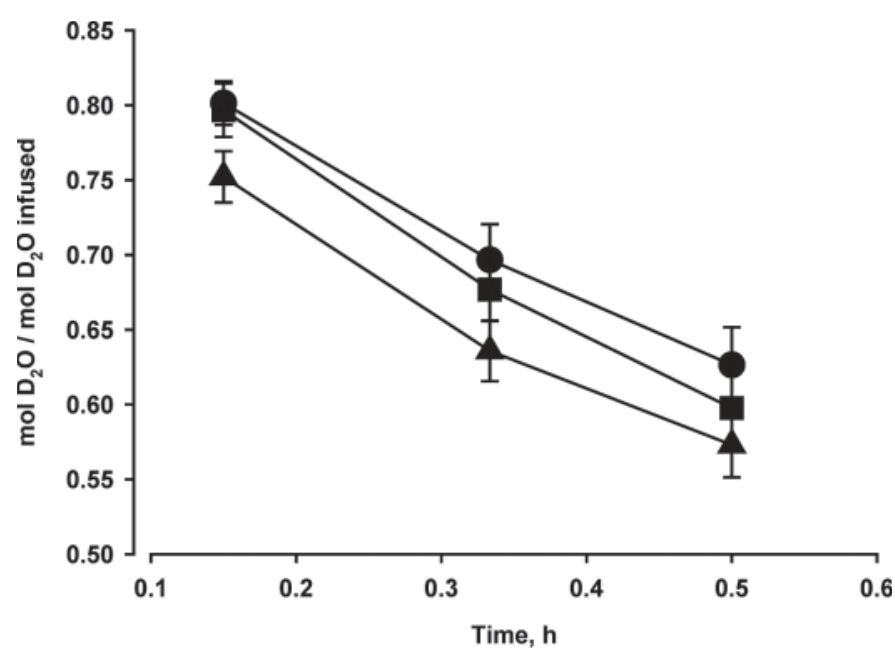

Figure 3. Reticuloruminal deuterium oxide $\left(\mathrm{D}_{2} \mathrm{O}\right)$ concentration relative to the infused amount of $\mathrm{D}_{2} \mathrm{O}$ as a function of time relative to ruminal bulk infusion of VFA buffer: control (ם), butyric $(\mathbf{\Lambda})$, ammonia (•), in lactating Holstein cows under washed rumen conditions. Each data point is the mean of 8 observations \pm SE.
4. Arterial blood ammonia was $64 \pm 14 \%$ higher with ammonia compared with control $(P=0.03)$, and the effect over time $(P<0.01)$ was related to an increase from time point 2 to 3 . Arterial blood concentration of urea increased $3.0 \mathrm{mmol} / \mathrm{L}$ in cows on high $\mathrm{CP}$ diets $(P<0.01)$ compared with cows on low $\mathrm{CP}$ diets. Data also showed an increase of arterial urea in the order of period $(P=0.01)$ and time $(P<0.01)$. The interaction between $\mathrm{CP}$ level and time $(P=0.03)$ indicated a somewhat faster increase with the arterial blood concentrations of urea in cows on high $\mathrm{CP}$ compared with cows on low $\mathrm{CP}$ diets, but this difference was numerically small. The arterial concentration of the blood flow marker pAH in plasma was, in general, higher with cows on low CP compared with cows on high CP diets. The 3-way interaction between CP level, buffer, and time on arterial pAH had no clear interpretation. Arterial plasma concentrations of glucose were affected by an interaction between buffer and time $(P=0.02)$, indicating that the concentration increased from time point 2 to 3 when exposed to ammonia buffer. Lactate concentrations in arterial plasma were affected by time $(P=0.02)$, showing an increase from time point 2 to 3 . The exposure to butyric buffer increased the arterial plasma concentration of BHBA 3-fold when compared with control $(P<0.01)$. The interaction between buffer and time $(P<0.01)$ showed that the arterial BHBA concentrations increased from time point 2 to 3 when exposed to butyric buffer.

\section{Ruminal Vein-Arterial Differences}

The concentration difference between the ruminal vein and the artery (RVA; Table 4) in the wash-buffer periods for acetate, propionate, butyrate, isobutyrate, valerate, and BHBA were all close to zero $(-0.019$ to $0.002 \mathrm{mmol} / \mathrm{L})$.

The RVA of acetate were affected by interactions between CP and buffer $(P<0.01)$, between buffer and time $(P=0.04)$, and between $\mathrm{CP}$ and time $(P$ $<0.01)$. We were not able to make a clear interpretation of these effects other than a decrease in relation to time $(P<0.01)$ between time point 2 and 3 . The RVA of propionate decreased with time $(P<0.01)$. The 
Table 3. Arterial variables in lactating dairy cows fed high $17.1 \%$ and low $12.9 \%$ CP diets exposed to 3 experimental buffers in temporarily evacuated and washed rumen

\begin{tabular}{|c|c|c|c|c|c|c|c|c|c|c|c|c|}
\hline \multirow[b]{2}{*}{ Item } & \multirow[b]{2}{*}{$\begin{array}{l}\text { Wash } \\
\text { buffer }\end{array}$} & \multicolumn{3}{|c|}{ High CP } & \multicolumn{3}{|c|}{ Low CP } & \multirow[b]{2}{*}{$\begin{array}{c}\text { SEM } \\
(\mathrm{n}=4)\end{array}$} & \multicolumn{4}{|c|}{$P$-value ${ }^{1}$} \\
\hline & & Ammonia & Butyric & Control & Ammonia & Butyric & Control & & $\mathrm{CP}$ & Buffer & $\begin{array}{l}\mathrm{CP} \times \\
\text { buffer }\end{array}$ & Time \\
\hline Whole blood pH & 7.42 & 7.44 & 7.44 & 7.43 & 7.46 & 7.44 & 7.43 & 0.015 & 0.72 & 0.55 & 0.24 & 0.08 \\
\hline $\begin{array}{l}\text { Whole blood, mmol/L } \\
\text { Acetate }\end{array}$ & 0.31 & 0.81 & 0.65 & 0.73 & 0.78 & 0.51 & 0.72 & 0091 & 0.53 & 020 & 019 & $<001$ \\
\hline Propionate & 0.010 & 0.030 & 0.037 & 0.012 & 0.012 & 0.036 & 0.016 & 0.0079 & 0.59 & $<0.01$ & 0.13 & 0.83 \\
\hline Butyrate** & 0.004 & 0.003 & 0.033 & 0.004 & 0.005 & 0.043 & 0.005 & 0.0044 & 0.37 & $<0.01$ & 0.50 & 0.04 \\
\hline Isobutyrate** & 0.001 & 0.003 & 0.003 & 0.003 & 0.002 & 0.004 & 0.002 & 0.0004 & 0.37 & 0.12 & 0.27 & 0.13 \\
\hline Valerate & 0.001 & 0.001 & 0.001 & $<0.001$ & 0.001 & 0.001 & $<0.001$ & 0.0008 & 0.82 & 0.76 & 0.59 & 0.89 \\
\hline $\mathrm{NH}_{3}$ & 0.17 & 0.43 & 0.24 & 0.23 & 0.47 & 0.31 & 0.32 & 0.043 & 0.22 & 0.03 & 0.56 & $<0.01$ \\
\hline Urea $* * * *$ & 3.52 & 5.35 & 5.41 & 5.50 & 2.44 & 2.40 & 2.43 & 0.30 & $<0.01$ & 0.86 & 0.28 & $<0.01$ \\
\hline Blood plasma, mmol/L & & & & & & & & & & & & \\
\hline$p$-Aminohippuric acid a $^{* * * * * *}$ & 0.081 & 0.070 & 0.068 & 0.073 & 0.091 & 0.087 & 0.093 & 0.0076 & 0.10 & 0.39 & 0.51 & 0.17 \\
\hline Glucose** & 3.88 & 4.36 & 3.94 & 4.12 & 4.46 & 3.96 & 4.25 & 0.27 & 0.81 & 0.30 & 0.79 & 0.49 \\
\hline L-Lactate & 0.17 & 0.28 & 0.26 & 0.28 & 0.23 & 0.25 & 0.25 & 0.085 & 0.80 & 0.95 & 0.44 & 0.02 \\
\hline BHBA** & 0.25 & 0.21 & 0.75 & 0.27 & 0.28 & 0.83 & 0.24 & 0.043 & 0.44 & $<0.01$ & 0.20 & 0.52 \\
\hline
\end{tabular}

${ }^{1} \mathrm{CP}=$ dietary $\mathrm{CP}$ level; buffer $=$ buffer treatment (ammonia, butyric, and control); time $=$ sample time $(\mathrm{n}=3,+9,+20,+30 \mathrm{~min})$.

${ }^{*}$ Period, $P<0.05 ;{ }^{* *}$ Buffer $\times$ Time, $P<0.05 ;{ }^{* * *} \mathrm{CP} \times$ Time, $P<0.05 ;{ }^{* * * *}$ Buffer $\times \mathrm{CP} \times$ Time, $P<0.05$.

Table 4. Right ruminal vein artery difference variables in lactating dairy cows fed high $17.1 \%$ and low $12.9 \%$ CP diet exposed to 3 experimental buffers in temporarily evacuated and washed rumen

\begin{tabular}{|c|c|c|c|c|c|c|c|c|c|c|c|c|}
\hline \multirow[b]{2}{*}{ Item } & \multirow[b]{2}{*}{$\begin{array}{l}\text { Wash } \\
\text { buffer }\end{array}$} & \multicolumn{3}{|c|}{ High CP } & \multicolumn{3}{|c|}{ Low CP } & \multirow[b]{2}{*}{$\begin{array}{c}\text { SEM } \\
(\mathrm{n}=4)\end{array}$} & \multicolumn{4}{|c|}{$P$-value ${ }^{1}$} \\
\hline & & Ammonia & Butyric & Control & Ammonia & Butyric & Control & & $\mathrm{CP}$ & Buffer & $\begin{array}{l}\mathrm{CP} \times \\
\text { buffer }\end{array}$ & Time \\
\hline \multicolumn{13}{|c|}{ Whole blood, mmol/L } \\
\hline Acetate $* * *^{* *}$ & -0.008 & $2.93^{\mathrm{ab}}$ & $1.28^{\mathrm{b}}$ & $1.92^{\mathrm{b}}$ & $3.30^{\mathrm{ab}}$ & $1.48^{\mathrm{b}}$ & $4.14^{\mathrm{a}}$ & 0.74 & 0.15 & 0.21 & $<0.01$ & $<0.01$ \\
\hline Propionate & 0.002 & $0.85^{\mathrm{ab}}$ & $0.98^{\mathrm{b}}$ & $0.73^{\mathrm{b}}$ & $1.01^{\mathrm{ab}}$ & $0.86^{\mathrm{b}}$ & $1.28^{\mathrm{a}}$ & 0.25 & 0.51 & 0.86 & $<0.01$ & $<0.01$ \\
\hline Butyrate* & -0.002 & 0.012 & 0.377 & 0.015 & 0.012 & 0.380 & 0.014 & 0.037 & 0.98 & $<0.01$ & 1.00 & $<0.01$ \\
\hline Isobutyrate & 0.001 & $0.055^{\mathrm{ab}}$ & $0.046^{\mathrm{ab}}$ & $0.041^{\mathrm{ab}}$ & $0.054^{\mathrm{ab}}$ & $0.031^{\mathrm{a}}$ & $0.063^{\mathrm{b}}$ & 0.012 & 0.85 & 0.41 & $<0.01$ & 0.01 \\
\hline Valerate & -0.0003 & 0.005 & 0.021 & 0.005 & 0.007 & 0.021 & 0.008 & 0.002 & 0.51 & $<0.01$ & 0.59 & $<0.01$ \\
\hline $\mathrm{NH}_{3}$ & 0.29 & $3.69^{\mathrm{ab}}$ & $2.63^{\mathrm{ab}}$ & $2.29^{\mathrm{ab}}$ & $3.86^{\mathrm{a}}$ & $1.95^{\mathrm{b}}$ & $3.72^{\mathrm{ab}}$ & 0.72 & 0.70 & 0.21 & $<0.01$ & 0.02 \\
\hline Urea** & -0.42 & -0.37 & -0.21 & -0.23 & -0.16 & -0.10 & -0.12 & 0.044 & $<0.01$ & 0.07 & 0.44 & $<0.01$ \\
\hline \multicolumn{13}{|c|}{ Blood plasma, mmol/L } \\
\hline Glucose* & -0.22 & -0.17 & -0.09 & -0.09 & -0.25 & -0.08 & -0.13 & 0.038 & 0.30 & 0.13 & 0.15 & $<0.01$ \\
\hline L-Lactate $* * *$ & 0.085 & $0.72^{\mathrm{ab}}$ & $0.42^{\mathrm{b}}$ & $0.46^{\mathrm{b}}$ & $0.72^{\mathrm{ab}}$ & $0.24^{\mathrm{b}}$ & $1.05^{\mathrm{a}}$ & 0.17 & 0.25 & 0.18 & $<0.01$ & 0.47 \\
\hline BHBA & -0.019 & 0.18 & 0.96 & 0.29 & 0.18 & 0.91 & 0.25 & 0.21 & 0.89 & 0.07 & 0.79 & 0.77 \\
\hline
\end{tabular}

$\stackrel{\oplus}{\mathrm{a}, \mathrm{b}}$ Means within row without a common superscript differ $(P<0.05)$ in relation to buffer.

Zo $\quad{ }^{1} \mathrm{CP}=$ dietary $\mathrm{CP}$ level; buffer $=$ buffer treatment (ammonia, butyric, and control); time $=$ sample time $(\mathrm{n}=3,+9,+20,+30 \mathrm{~min})$.

$\infty \quad *$ Buffer $\times$ Time, $P<0.05 ;{ }^{* *} \mathrm{CP} \times$ Time, $P<0.05 ; * * *$ Buffer $\times \mathrm{CP} \times$ Time, $P<0.05$ 


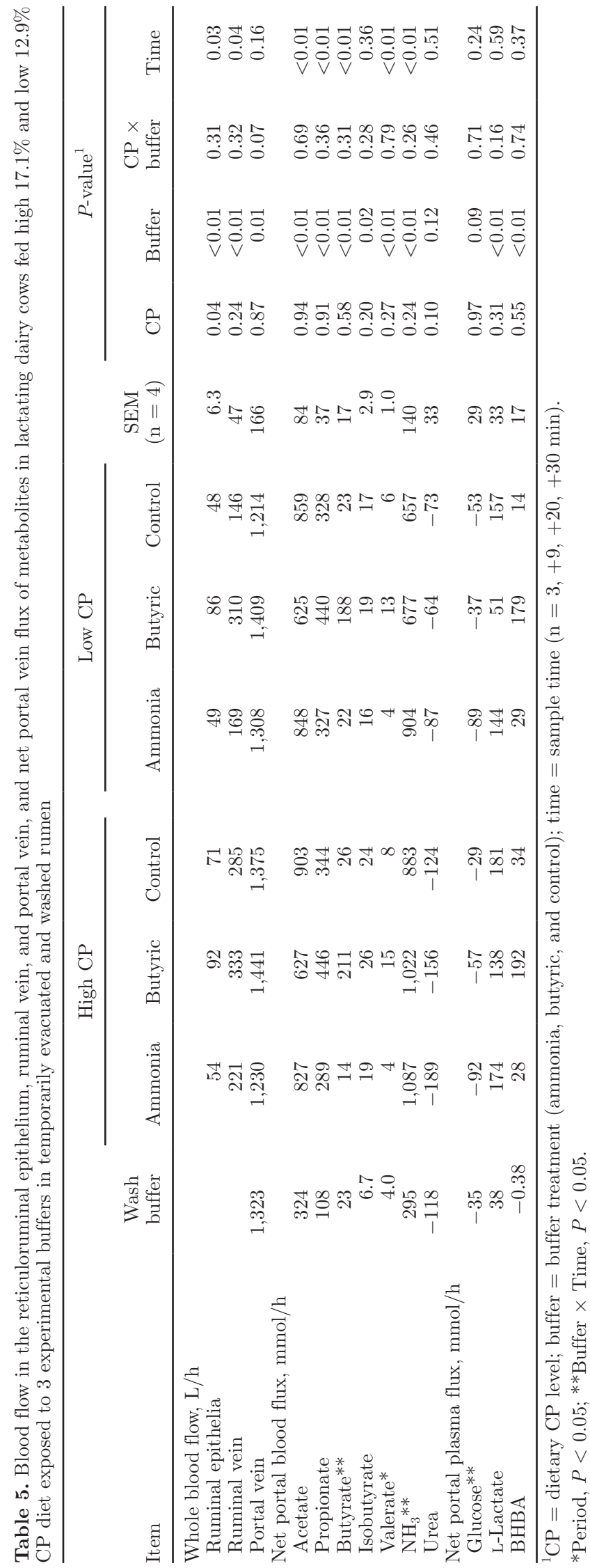

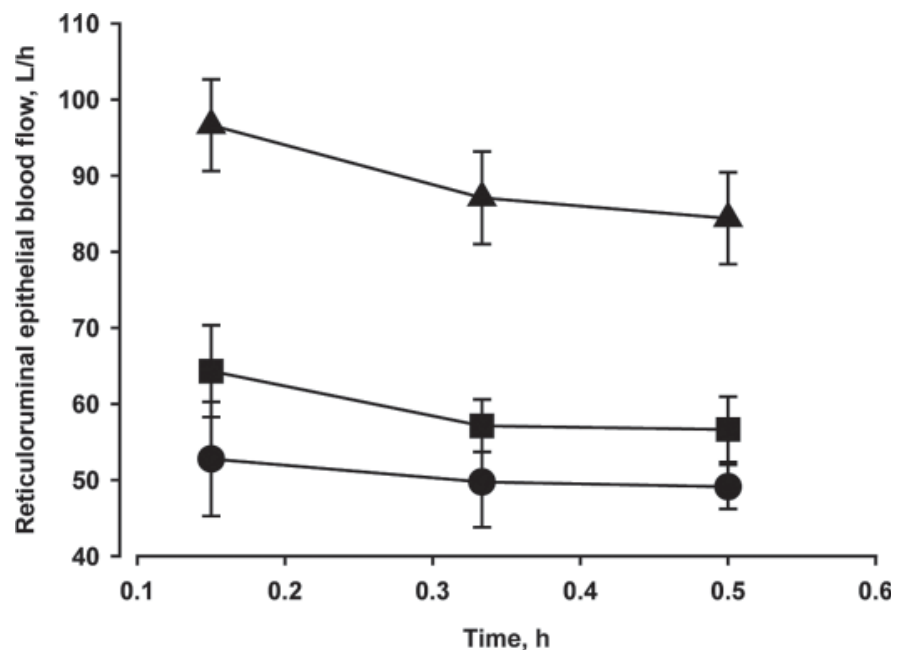

Figure 4. Reticuloruminal epithelia blood flow (ruminal clearance of deuterium oxide, $\mathrm{D}_{2} \mathrm{O}$ ) as a function of time relative to ruminal bulk infusion of VFA buffer: control ( $\mathbf{\square})$, butyric $(\mathbf{\Lambda})$, ammonia $(\mathbf{\bullet})$, in lactating Holstein cows under washed rumen conditions. Each data point is the mean of 8 observations \pm SE.

interaction between CP level and buffer $(P<0.01)$ for RVA of propionate indicated that RVA of propionate was greatest with cows on low CP diets when exposed to control buffer.

A clear effect of butyric buffer on the RVA of butyrate $(P<0.01)$ was observed: the difference increased 25 -fold in butyric compared with control. The interaction between buffer and sample on RVA of butyrate $(P<0.01)$ was related to a decrease over time when cows were exposed to butyric buffer. The interaction between CP level and buffer on RVA of isobutyrate $(P<0.01)$ was related to a higher RVA for cows on low $\mathrm{CP}$ exposed to control buffer compared with other combinations of $\mathrm{CP}$ and buffers. The effect of time $(P$ $=0.01)$ on RVA of isobutyrate was related to a decrease over time that was most apparent between time points 2 and 3. The RVA of valerate was affected by buffer $(P<0.01)$, showing an increased difference in cows exposed to butyric buffer compared with control. The RVA of valerate decreased with time $(P<0.01)$. The RVA of $\mathrm{NH}_{3}$ was affected by an interaction between $\mathrm{CP}$ and buffer $(P<0.01)$, reflecting a decreased difference among cows on low CP compared with high $\mathrm{CP}$ when exposed to the butyric buffer. The RVA for urea was negative, indicating a net release of urea to the rumen. The net release of urea was greater $(P<0.01$; Table 4 ) in cows on high $\mathrm{CP}$ diets compared with those on low $\mathrm{CP}$ diets. The interaction between $\mathrm{CP}$ level and time $(P<0.01)$ indicated that the RVA of urea became more negative with time for cows on low CP compared with cows on high CP diets. The RVA of glucose was affected by an interaction between buffer and time $(P$ 
$=0.02)$, showing an increasing use of glucose by the rumen in ammonia buffer between time points 2 and 3 compared with control. The RVA of L-lactate was affected by an interaction between CP level, buffer, and time $(P<0.01)$, indicating higher RVA in cows on low $\mathrm{CP}$ when exposed to control buffer compared with cows exposed to butyrate buffer at time points 2 and 3 . Because of large variations in the estimate of RVA for BHBA in butyric buffer periods, only a tendency $(P=0.07)$ of buffer effect was observed. The tendency reflected a $247 \pm 85 \%$ increase in butyric compared with control.

\section{Blood Flow}

Ruminal clearance of $\mathrm{D}_{2} \mathrm{O}$ (Figure 4; Table 5) was considered as absorptive reticuloruminal epithelial blood flow and was affected by CP level and buffer $(P$ $=0.04, P<0.01$, respectively). High $\mathrm{CP}$ increased $\mathrm{D}_{2} \mathrm{O}$ clearance, as did butyric buffer compared with control $(P<0.01)$. The epithelial blood flow increased $49 \pm$ $11 \%$ in butyric compared with control and $72 \pm 13 \%$ in butyric compared with ammonia (both $P<0.01$ ). The epithelial blood flow in butyric and control decreased with sampling time $(P=0.03)$. The correlation between epithelial blood flow and ruminal disappearance of propionate was $\mathrm{r}=0.56(P<0.01)$.

The ruminal vein blood flow was calculated from dilution of ruminal $\mathrm{D}_{2} \mathrm{O}$ concentration to ruminal vein concentration using the ruminal epithelial blood flow as $\mathrm{D}_{2} \mathrm{O}$ source. An effect of buffer $(P<0.01)$ was observed, increasing the ruminal vein blood flow by 49 $\pm 18 \%$ in butyric compared with control. The average ruminal vein blood flow was 195,322 , and $216 \pm 34$ $\mathrm{L} / \mathrm{h}$ in ammonia, butyric, and control, respectively. As for ruminal epithelial blood flow, ruminal vein blood flow decreased with time $(P=0.04)$.

Portal blood flow (Table 5) was, on average, 1,294 $\pm 118 \mathrm{~L} / \mathrm{h}$ with control and was numerically decreased to $1,269 \pm 118 \mathrm{~L} / \mathrm{h}$ with ammonia. Butyric treatment increased $(P<0.01)$ portal blood flow by $10 \pm 3.9 \%$ to $1,425 \pm 118 \mathrm{~L} / \mathrm{h}$ compared with control. The portal blood flow was not affected by time of sampling $(P=$ $0.16)$ or $\mathrm{CP}$ level $(P=0.87)$.

\section{Net Portal Fluxes}

The net portal flux of acetate (Table 5) was lowest in butyric compared with control buffer and decreased over time (both $P<0.01$ ). Butyric buffer exposure increased $(P<0.01)$ the net portal flux of propionate (Figure 5 ) by $32 \pm 6 \%$ and that of valerate by $108 \pm$ $10 \%$ compared with control, with a reduction over time $(P<0.01)$. The net portal flux of isobutyrate with

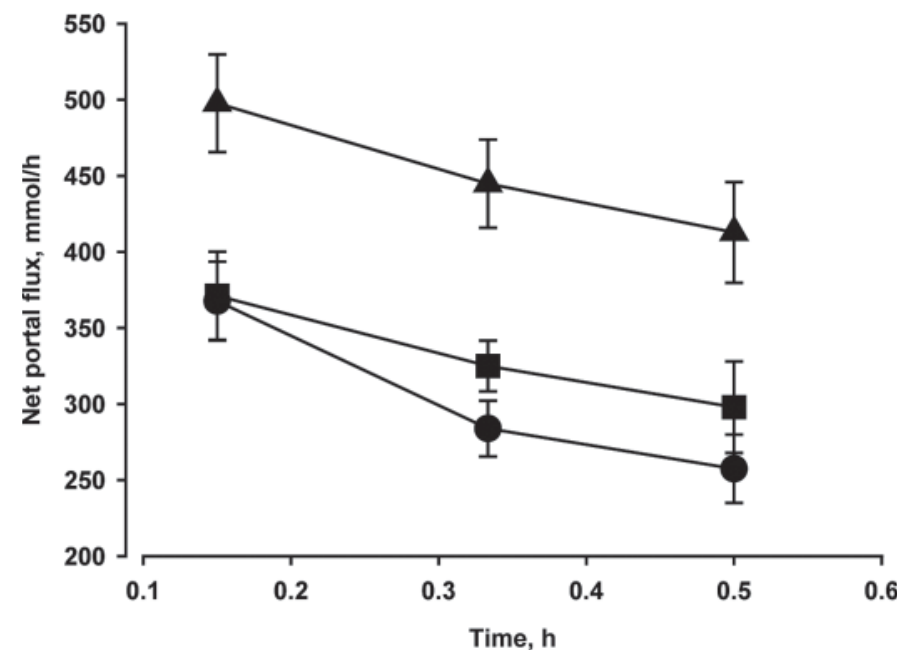

Figure 5. Net portal flux of propionate as a function of time relative to ruminal bulk infusion of VFA buffer: control ( $\mathbf{\square})$, butyric $(\mathbf{\Lambda})$, ammonia $(\bullet)$, in lactating Holstein cows under washed rumen conditions. Each data point is the mean of 8 observations $\pm \mathrm{SE}$.

butyric buffer exposure was not different from control but increased $25 \pm 8 \%$ in relation to ammonia buffer exposure $(P<0.01)$. The net portal flux of butyrate increased $705 \pm 84 \%$ in butyric compared with control $(P<0.01)$. The interaction between buffer and time $(P$ $<0.01$ ) indicated a decrease in the net portal flux of butyrate over time when cows were exposed to butyric compared with other buffers.

The net portal plasma flux of $\mathrm{NH}_{3}$ increased $29 \pm$ $6 \%$ in ammonia compared with control $(P<0.01)$. The interaction between buffer and time indicated that the difference between ammonia and control was largest at time point 2. The net portal flux of urea was negative, indicating a net release of urea to the gut. A tendency $(P=0.10)$ for a greater urea uptake of urea across the gut in cows on high $\mathrm{CP}$ was measured. However, urea net portal flux was not affected by buffer $(P=$ 0.12 ). The net portal flux of glucose showed net use by the portal-drained viscera. The interaction between buffer and time $(P=0.04)$ indicated an increased portal-drained viscera use of glucose at time point 2 when exposed to ammonia buffer. The net portal flux of L-lactate was $44 \pm 10 \%$ lower and the net portal flux of BHBA was $670 \pm 64 \%$ higher in butyric compared with control $(P<0.01)$.

\section{Ruminal Vein Recovery of VFA}

The recovery of ruminal acetate, propionate, and isobutyrate into ruminal vein blood was not affected by buffer $(P=0.19$ to $P=0.83)$, dietary $\mathrm{CP}(P=$ 0.19 to $P=0.82)$, or time $(P=0.09$ to $P=0.96)$. The recoveries were, on average, $1.10 \pm 0.17,0.66 \pm 0.034$, 
and $0.93 \pm 0.10$ for acetate, propionate, and isobutyrate, respectively.

\section{DISCUSSION}

The mechanism of ruminal VFA absorption has been studied for decades and it is still not fully elucidated. The present study aims to contribute to modeling cow responses to changes in ruminal fermentation and the effects of fermentation on ruminal VFA kinetics through changes in the epithelial blood flow. We hypothesized that the effective reticuloruminal epithelial blood flow is affecting net transepithelial VFA flux and thereby the efficiency by which VFA are absorbed from ruminal fluid.

\section{Reticuloruminal Epithelial Blood Flow}

The present study estimated epithelial and ruminal vein blood flow from the ruminal clearance of $\mathrm{D}_{2} \mathrm{O}$. This method has not been extensively examined in ruminants and the 3 assumptions related to the methodology are as follows: (1) the ruminal $\mathrm{D}_{2} \mathrm{O}$ has to be in equilibrium throughout the rumen, (2) ruminal influx and outflow of liquid has to be accounted for, and (3) ruminal $\mathrm{D}_{2} \mathrm{O}$ has to equilibrate across the epithelium so fast that ruminal buffer concentration of $\mathrm{D}_{2} \mathrm{O}$ equals epithelial blood concentrations of $\mathrm{D}_{2} \mathrm{O}$.

In regard to assumption (1), the intraruminal equilibration of $\mathrm{D}_{2} \mathrm{O}$ was ensured through mixing $\mathrm{D}_{2} \mathrm{O}$ into the buffers before addition to the rumen and continuous agitation of ruminal buffers with gas dispersed through a fine mesh during the trial.

For assumption (2), a reliable estimate of the ruminal pool of $\mathrm{D}_{2} \mathrm{O}$ throughout the trial was essential for a reliable estimate of the ruminal clearance (epithelial blood flow). The pool of $\mathrm{D}_{2} \mathrm{O}$ in the buffer was diluted with the residual rumen water upon buffer entry, and with physiological water (saliva and epithelial water influx) as the trial progressed. In addition, $\mathrm{D}_{2} \mathrm{O}$ leaves the rumen through passage to the omasum (Peters et al., 1990). All 3 variables affect the total pool size of ruminal $\mathrm{D}_{2} \mathrm{O}$ over time. Because of large variations among cows and buffers, the ruminal buffer passage, dilution with physiological water, and ruminal residual water were estimated individually for each combination of cow and buffer using a dynamic simulation model. The model was able to find a local solution for each of the small data sets used. The set of initial values that maximized the log-likelihood function and minimized standard errors (SE <0.0094\%) was chosen. Choices were also assessed visually using residual plots to ensure the absence of systematic bias. This approach improved the accuracy of ruminal $\mathrm{D}_{2} \mathrm{O}$ clearance and VFA disap- pearance when using the 24 sets of parameter estimates in the numerical calculation in comparison to simple log-transformation of data and extrapolation.

Concerning assumption (3), tritiated water clearance has been used for estimation of epithelial blood flow in segments of the small intestinal and hindgut in monogastric animals (Winne, 1972). The method has also been used to measure reticuloruminal epithelial blood flow in sheep (Dobson, 1979) and in cows (Dobson et al., 1971, 1976). Dobson (1979) concluded that ruminal clearance of tritiated water underestimates epithelial blood flow when evaluated against flow measured with radioactive microsphere particles. However, the study was conducted on fasted, anesthetized, ram lambs (21 $\pm 2.1 \mathrm{~kg}$ of $\mathrm{BW}$ ) with the reticulorumen isolated from distal compartments of the gastrointestinal tract by ligatures. These experimental conditions deviate substantially from the normal physiological conditions and might have affected rumen function and blood flow. Moreover, because ruminal clearance was estimated over a period of $120 \mathrm{~min}$ with 2 ruminal injections of tritiated water, the ability to estimate epithelial blood flow by water equilibration might have been affected. The duration of the study of Dobson (1979) allowed time for building a high arterial background of tritiated water, but it is not clear whether the author corrected the calculated flows for arterial concentration of tritiated water. One of the major differences between the 2 techniques is that microsphere particles measure blood flow in all epithelia, whereas tritiated water- $\mathrm{D}_{2} \mathrm{O}$ clearance only estimates blood flow in the active absorbing epithelium submerged in rumen fluid. When addressing epithelial blood flow as a possible limitation to reticulorumen absorption of VFA, blood flowing through tissue not exposed to VFA has to be excluded. The accuracy of measurements of blood flow in the active absorptive tissue of the reticulorumen with the microsphere technique would rely on a clear distinction between epithelium submerged and not submerged in rumen fluid, and a microscopic dissection of the tissue for analytical purposes, both difficult to obtain.

The rumen epithelial blood flows observed in the present study were 51,89 , and $59 \pm 4.5 \mathrm{~L} / \mathrm{h}$ and the related ruminal vein blood flows, albeit with few observations on low $\mathrm{CP}$, were 195,322 , and $216 \pm 34 \mathrm{~L} / \mathrm{h}$ for ammonia, butyric, and control, respectively. Recent studies in dairy cows at similar production levels, using flow probes on the right ruminal artery, reported right rumen arterial blood flows of 96 to $125 \mathrm{~L} / \mathrm{h}$ (Girard et al., 2009; Girard and Desrochers, 2010). Assuming blood flow of the right ruminal artery to be half of the total reticuloruminal blood supply, the estimates across studies and techniques are in good agreement. The soundness of the estimates on ruminal vein blood 
flow are indicated by the ruminal vein recovery of ruminal acetate and isobutyrate $(1.10 \pm 0.17$ and $0.93 \pm$ 0.10 , respectively), which is in agreement with expected low metabolism of these 2 compounds by the ruminal epithelium (Kristensen and Harmon, 2004a,b).

The data of the present study support the conclusion that epithelial blood flow responds to chemical changes in the ruminal buffer. As observed earlier, ruminal butyrate stimulates rumen epithelial blood flow (Dobson et al., 1971) and ruminal vein blood flow (Remond et al., 1993). In the latter study, the ruminal blood supply increased by $60 \%$ with an increase in ruminal butyrate from 5 to $25 \mathrm{mmol} / \mathrm{L}$. In the present study, increasing ruminal butyrate from 4 to $36 \mathrm{mmol} / \mathrm{L}$ increased the ruminal vein blood flow by $65 \pm 19 \%$.

The partition of blood flow between the active absorptive epithelium and other tissues of the reticulorumen was, on average, 31 and $69 \%$, respectively. This was in contrast to Barnes et al. (1983) and Von Engelhardt and Hales (1977), who reported that the epithelium accounted for 92 and $95 \%$ of the reticulorumen blood supply, respectively. The variance between studies might be related to the choice of method; $\mathrm{D}_{2} \mathrm{O}$ clearance only measures the active absorbing part of the epithelium.

\section{Net Fluxes of VFA}

Reticulorumen absorption of VFA is commonly thought to occur by passive diffusion of non-ionized VFA as well as by carrier-mediated transport across the epithelium (for reviews, see Bugaut, 1987; Bergman, 1990; Dijkstra, 1994; Aschenbach et al., 2011). This dual process is in agreement with the VFA concentration of ruminal fluid and ruminal $\mathrm{pH}$ as important drivers of ruminal VFA absorption (Dijkstra et al., 1993; López et al., 2003). However, the absorption of acetate, propionate, and butyrate in lactating dairy cows did not increase to the extent expected (Dijkstra et al., 1993). Only propionate and butyrate absorption was affected by low ruminal $\mathrm{pH}$. Therefore, a mismatch exists between the availability of non-ionized VFA and the theory of passive diffusion as the only limitation for ruminal absorption. However, as hypothesized, ruminal epithelial blood flow may limit the absorption of ruminal VFA, resulting in a nonexponential relationship when blood is saturated with VFA. That is, the absorption of VFA is affected by VFA permeability and blood flow to the epithelium. With low epithelial blood flow, net VFA absorption is limited by removal with blood and not permeability.

Propionate was the VFA marker in the present study because acetate and butyrate concentrations were manipulated across treatments. The ruminal disappearance of propionate increased $30 \pm 12 \%$ in butyric compared with ammonia treatment. Because propionate was not varied among buffers, the effect can be explained by two factors: (1) increased epithelial metabolism of propionate increases the ruminal absorption, and (2) increased blood flow increases the removal of propionate from the serosal side of the epithelium, which increases absorption of ruminal propionate.

Butyrate is known to affect the epithelial metabolism of fermentation products. However, evidence suggests that epithelial metabolism has higher affinity for butyrate than for acetate and propionate (Kristensen and Harmon, 2004a). High butyrate concentration would therefore be assumed to competitively inhibit metabolism of propionate, increasing the intracellular concentration and decreasing absorption; however, the opposite effect of increased butyrate was observed. The observed increase in disappearance of propionate was followed by an increase in net portal flux of propionate, indicating minimal change in epithelial metabolism of propionate. The net portal flux of propionate is a combined flux of ruminal, omasal, and hindgut absorption, and variation among partitions of the flux cannot be excluded. However, ruminal vein recovery of ruminal propionate was not affected by treatment, indicating that increased epithelial metabolism cannot have driven the extra propionate uptake with butyric buffer. The disappearance rate of propionate in the present study corresponds with reports in steers under the same experimental circumstances (Kristensen and Harmon, 2004a). However, Kristensen and Harmon (2004a) did not observe a significant increase in VFA disappearance related to the same increase in ruminal butyrate, which might have been caused by the steers being fed at a lower plane of nutrition and therefore having a lower dynamic range of epithelial blood flow compared with the high-yielding dairy cows used in the present study. Ruminal disappearance and net portal flux of propionate followed the same pattern as epithelial blood flow; that is, propionate uptake from the rumen increased with butyric treatment, as did ruminal $\mathrm{D}_{2} \mathrm{O}$ clearance. The correlation between ruminal disappearance of propionate and epithelial blood flow $(\mathrm{r}=0.56, P<0.01)$ supports the concept that epithelial blood flow affects removal of propionate. However, variation among cows or a curvilinear relation between increasing epithelial blood flow and ruminal absorption of propionate may have affected the Pearson correlation estimate.

Isobutyrate is generally considered not to be metabolized by the ruminal epithelium (Kristensen et al., 2000; Kristensen and Harmon, 2004b) and is therefore considered the best marker for the effect of epithelial blood flow on ruminal VFA absorption. Net portal appearance of isobutyrate increased $24 \pm 8 \%$ from ammonia to butyric buffers, in line with the increase 
in propionate net portal flux. Kristensen and Harmon (2004a) observed decreasing net portal flux of isobutyrate with increasing ruminal butyrate, a finding that is in conflict with the results of the present study. The ruminal vein recovery of isobutyrate of the present study supports the earlier reports of low epithelial metabolism. The increased net portal flux of propionate and isobutyrate with butyric buffer is in line with the hypothesized effect of epithelial blood flow on ruminal absorption. Data from the present study strongly suggest that epithelial blood flow affects ruminal absorption kinetics. The proportionality between net flux and epithelia blood flow also indicates that the permeability of the epithelium becomes a more important limitation to absorption rate as blood flow increases.

\section{Implications for VFA Absorption Models}

The absorption mechanism of passive diffusion of non-ionized VFA has earlier been justified from downstream absorption of VFA through the large concentration gradient between the lumen and blood. Considering the relatively low epithelial blood flow and the massive absorption of VFA, the concentration differences between the rumen and epithelial blood were no more than approximately 5:1 under the experimental conditions applied in the present study. With the relatively low concentration gradient and passive diffusion as the main driver of VFA absorption, the flux of VFA cannot be described as unidirectional. In situations with low epithelial blood flow, the effluxes of VFA increase as an effect of increasing intracellular and blood concentration of VFA. Even though most ruminal models describe the absorption of VFA as proportional to the ruminal pool (Baldwin et al., 1987; Danfær, 1990), the model of Dijkstra (1993) is the only one that utilizes nonlinear equations to describe the relationship between VFA availability and absorption. However, these models are driven entirely from ruminal variables of concentration, volume, and $\mathrm{pH}$. Regardless of the use of linear or nonlinear representations, these models will provide biased predictions to the extent that blood flow affects absorption. Thus, the present work suggests that a revised model of VFA absorption that includes a representation of the effects of epithelial blood flow on bidirectional fluxes or net absorption is necessary to describe the underlying dynamics of VFA exchange among rumen, epithelium, and blood.

\section{Rumen Epithelial VFA Metabolism}

The net portal flux of valerate was $226 \pm 15 \%$ greater $(P<0.01)$ for butyric compared with ammonia, which is in line with observations in steers (Kristensen and Harmon, 2004a) and indicates competitive inhibition between butyrate and valerate. When epithelial metabolism of valerate decreased, L-lactate production decreased, showing that the propionyl-CoA product of $\beta$-oxidation of valerate is a main substrate for $\mathrm{ru}-$ men epithelial L-lactate synthesis. The importance of valerate as a substrate for rumen epithelial L-lactate synthesis is in agreement with production of L-lactate from rumen epithelium incubated with valerate in vitro (Weigand et al., 1975). However, the difference in net portal flux of L-lactate with butyrate compared with other buffers cannot be accounted for solely by changes in valerate metabolism, so either propionate metabolism or metabolism of other substrates as glucose was affected by butyrate. Because propionate sequestration by the ruminal epithelium is relatively low (Kristensen and Harmon, 2004b), small changes in propionate metabolism, as affected by butyrate in the present study, are difficult to detect. The metabolic activity of ruminal epithelium is clearly affected by the absorption of fermentation product, especially butyrate.

\section{Relationship Between Rumen Epithelial Blood Flow and Urea Transport}

Strong evidence suggests that the transport of blood urea across gut epithelium is regulated by mass action and that the dietary CP level affects the permeability of the tissue (Kristensen et al., 2010). Fermentation end-products, especially $\mathrm{CO}_{2}$ and butyrate, are also known to enhance gut entry of urea (Thorlacius et al., 1971). Increased blood flow to the main site of urea recycling (reticulorumen) can be hypothesized to positively affect the rate of recycling. Rémond et al. (1993) observed a 30\% increase in urea net ruminal vein flux with a $60 \%$ increase in right ruminal artery blood flow. However, the present study does not point to the same sensitivity to blood flow in cattle. This might relate to a short-term effect of ruminal ammonia observed to decrease urea transport postprandially in dairy cattle (Røjen et al., 2011) to work in conjunction with the long-term diet-induced adaptation of epithelial urea transport. In the present study, both the ruminal ammonia concentration and the net portal flux of ammonia appeared high compared with the fluxes observed in the same cows when fed and having normal rumen function (Kristensen et al., 2010). To the extent that the rumen epithelium permeability of urea is high, we expected that urea transport would be limited by epithelial blood flow; however, under the present experimental conditions, urea transport appeared limited primarily by epithelial permeability and not epithelial blood flow. 


\section{CONCLUSIONS}

Rumen epithelial blood flow under washed rumen conditions is positively correlated to ruminal disappearance of propionate and absorption kinetics of VFA from the rumen. The study shows that description of ruminal epithelial blood flow might be essential in future models of ruminal VFA kinetics and ruminal environment.

\section{ACKNOWLEDGMENTS}

We gratefully acknowledge Birgit H. Løth, Anne Krustrup, Mogens Larsen, Pia Jensen, Marie Engbak, Thorkild N. Jakobsen, Ole H. Olsen, and the barn staff at Faculty of Agricultural Sciences, Aarhus University (Tjele, Denmark) for skillful technical and expert assistance. This project was funded by the Commission of the European Communities (Brussels, Belgium; FP7, KBBE-2007-1), the Directorate for Food, Fisheries and Agri Business (Copenhagen, Denmark; \#3304-VMP05-005), the Danish Cattle Federation (\#Stivelsesprojektet; Aarhus, Denmark), and the Danish Ministry of Food, Agriculture and Fisheries, Copenhagen, Denmark.

\section{REFERENCES}

Allen, M. S. 1996. Physical constraints on voluntary intake of forages by ruminants. J. Anim. Sci. 74:3063-3075.

Aschenbach, J. R., S. Bilk, G. Tadesse, F. Stumpff, and G. Gabel. 2009. Bicarbonate-dependent and bicarbonate-independent mechanisms contribute to nondiffusive uptake of acetate in the ruminal epithelium of sheep. Am. J. Physiol. Gastrointest. Liver Physiol. 296:G1098-G1107.

Aschenbach, J. R., G. B. Penner, F. Stumpff, and G. Gäbel. 2011. Role of fermentation acid absorption in the regulation of ruminal $\mathrm{pH}$. J. Anim. Sci. 89:1092-1107. doi:10.2527/jas.2010-3301.

Baldwin, R. L., J. H. M. Thornley, and D. E. Beever. 1987. Metabolism of the lactating cow. 2. Digestive elements of a mechanistic model. J. Dairy Res. 54:107-131.

Barnes, R. J., R. S. Comline, and A. Dobson. 1983. Changes in the blood flow to the digestive organs of sheep induced by feeding. Q. J. Exp. Physiol. 68:77-88.

Bergman, E. N. 1990. Energy contributions of volatile fatty-acids from the gastrointestinal-tract in various species. Physiol. Rev. 70:567-590.

Binnerts, W. T., A. T. Vantkloo, and A. M. Frens. 1968. Soluble chromium indicator measured by atomic absorption in digestion experiments. Vet. Rec. 82:470.

Bugaut, M. 1987. Occurrence, absorption and metabolism of short chain fatty-acids in the digestive-tract of mammals. Comp. Biochem. Physiol. B 86:439-472.

Danfær, A. 1990. A dynamic model of nutrient digestion and metabolism in lactating dairy cows. Thesis, Report 671. National Institute of Animal Science, Foulum, Denmark.

Dijkstra, J. 1993. Mathematical modeling and integration of rumen fermentation processes. PhD Thesis. Agricultural University of Wageningen, Wageningen, the Netherlands.

Dijkstra, J. 1994. Production and absorption of volatile fatty acids in the rumen. Livest. Prod. Sci. 39:61-69.

Dijkstra, J., H. Boer, J. Vanbruchem, M. Bruining, and S. Tamminga. 1993. Absorption of volatile fatty acids from the rumen of lactat- ing dairy cows as influenced by volatile fatty acid concentration, $\mathrm{pH}$ and rumen liquid volume. Br. J. Nutr. 69:385-396.

Dobson, A. 1979. Choice of models relating tritiated water absorption to subepithelial blood flow in the rumen of sheep. J. Physiol. 297:111-121.

Dobson, A., A. F. Sellers, and V. H. Gatewood. 1976. Absorption and exchange of water across rumen epithelium. Am. J. Physiol. 231:1588-1594.

Dobson, A., A. F. Sellers, and S. O. Thorlaci. 1971. Limitation of diffusion by blood flow through bovine ruminal epithelium. Am. J. Physiol. 220:1337-1343.

Girard, C. L., C. Benchaar, J. Chiquette, and A. Desrochers. 2009 Net flux of nutrients across the rumen wall of lactating dairy cows as influenced by dietary supplements of folic acid. J. Dairy Sci. 92:6116-6122.

Girard, C. L., and A. Desrochers. 2010. Net flux of nutrients across splanchnic tissues of lactating dairy cows as influenced by dietary supplements of biotin and vitamin $\mathrm{B}_{12}$. J. Dairy Sci. 93:16441654 .

Harvey, R. B., and A. J. Brothers. 1962. Renal extraction of paraaminohippurate and creatinine measured by continuous in vivo sampling of arterial and renal-vein blood. Ann. N. Y. Acad. Sci. 102:46-54.

Kristensen, N. B. 2000. Quantification of whole blood short-chain fatty acids by gas chromatographic determination of plasma 2-chloroethyl derivatives and correction for dilution space in erythrocytes. Acta Agric. Scand. Anim. Sci. 50:231-236.

Kristensen, N. B., A. Danfær, B. A. Røjen, B.-M. L. Raun, M. R. Weisbjerg, and T. Hvelplund. 2002. Metabolism of propionate and 1,2-propanediol absorbed from the washed reticulorumen of lactating cows. J. Anim. Sci. 80:2168-2175.

Kristensen, N. B., A. Danfær, V. Tetens, and N. Agergaard. 1996. Portal recovery of intraruminally infused short-chain fatty acids in sheep. Acta Agric. Scand. Anim. Sci. 46:26-38.

Kristensen, N. B., G. Gäbel, S. G. Pierzynowski, and A. Danfær. 2000. Portal recovery of short-chain fatty acids infused into the temporarily-isolated and washed reticulo-rumen of sheep. Br. J. Nutr. $84: 477-482$

Kristensen, N. B., and D. L. Harmon. 2004a. Effect of increasing ruminal butyrate absorption on splanchnic metabolism of volatile fatty acids absorbed from the washed reticulorumen of steers. J. Anim. Sci. 82:3549-3559.

Kristensen, N. B., and D. L. Harmon. 2004b. Splanchnic metabolism of volatile fatty acids absorbed from the washed reticulorumen of steers. J. Anim. Sci. 82:2033-2042.

Kristensen, N. B., A. Storm, B. M. L. Raun, B. A. Røjen, and D. L. Harmon. 2007. Metabolism of silage alcohols in lactating dairy cows. J. Dairy Sci. 90:1364-1377.

Kristensen, N. B., A. C. Storm, and M. Larsen. 2010. Effect of dietary nitrogen content and intravenous urea infusion on ruminal and portal-drained visceral extraction of arterial urea in lactating Holstein cows. J. Dairy Sci. 93:2670-2683.

López, S., F. D. D. Hovell, J. Dijkstra, and J. France. 2003. Effects of volatile fatty acid supply on their absorption and on water kinetics in the rumen of sheep sustained by intragastric infusions. J. Anim. Sci. 81:2609-2616.

Marsh, W. H., B. Fingerhut, and H. Miller. 1965. Automated and manual direct methods for the determination of blood urea. Clin. Chem. 11:624-627.

Peters, J. P., R. Y. W. Shen, J. A. Robinson, and S. T. Chester. 1990. Disappearance and passage of propionic acid from the rumen of the beef steer. J. Anim. Sci. 68:3337-3349.

Rémond, D., J. P. Chaise, E. Delval, and C. Poncet. 1993. Net transfer of urea and ammonia across the ruminal wall of sheep. J. Anim. Sci. 71:2785-2792.

Røjen, B. A., P. K. Theil, and N. B. Kristensen. 2011. Effects of nitrogen supply on inter-organ fluxes of urea-N and renal urea-N kinetics in lactating Holstein cows. J. Dairy Sci. 94:2532-2544.

SAS Institute. 2003. The SAS System for Windows. Version 9.1. SAS Institute Inc., Cary, NC. 
Scott, A., and I. C. Gardner. 1973. Papillar in the forestomach of the sheep. J. Anat. 116:255-267.

Storm, A. C., and N. B. Kristensen. 2010. Effects of particle size and dry matter content of a total mixed ration on intraruminal equilibration and net portal flux of volatile fatty acids in lactating dairy cows. J. Dairy Sci. 93:4223-4238.

Storm, A. C., and N. B. Kristensen. 2011. Erratum to "Effects of particle size and dry matter content of a total mixed ration on intraruminal equilibration and net portal flux of volatile fatty acids in lactating dairy cows" (J. Dairy Sci. 93:4223-4238). J. Dairy Sci. 94:532-535.

Thorlacius, S. O., A. Dobson, and A. F. Sellers. 1971. Effect of carbon dioxide on urea diffusion through bovine ruminal epithelium. Am. J. Physiol. 220:162-170.
Von Engelhardt, W., and J. Hales. 1977. Partition of capillary blood flow in rumen, reticulum, and omasum of sheep. Am. J. Physiol. 232:E53-E56

Weigand, E., J. W. Young, and A. D. McGilliard. 1975. Volatile fatty acid metabolism by rumen mucosa from cattle fed hay or grain. J Dairy Sci. 58:1294-1300.

Williams, C. H., D. J. David, and O. Iismaa. 1962. The determination of chromic oxide in faeces samples by atomic absorption spectrophotometry. J. Agric. Sci. 59:381-385.

Winne, D. 1972. The influence of blood flow and water net flux on the absorption of tritiated water from the jejunum of the rat. Naunyn Schmiedebergs Arch. Pharmacol. 272:417-436. 